\title{
CDiC Textbook of Pediatric Diabetes: Book review
}

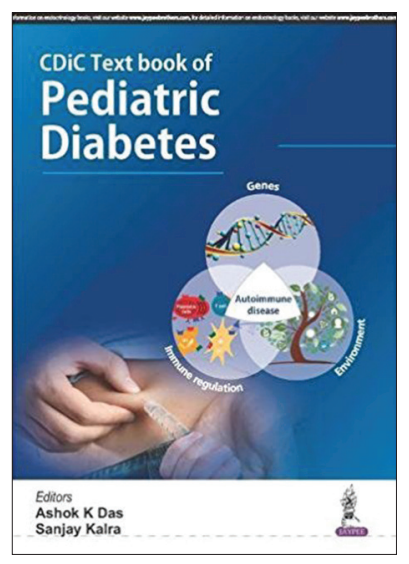

Authors: Ashok K Das, Sanjay Kalra

Edition: $1^{\text {st }}$ Edition

Year of Publication: 2017

Publisher: Jaypee Brothers Medical Publishers

Price: Not mentioned

ISBN: 978-9352700868

Pages: 350

Pediatric diabetes is a challenging disorder to manage and often the onus of the treatment falls on the shoulders of those who may not have specialized training in this speciality. Despite the availability of detailed textbooks on this topic, the need for a concise yet comprehensive source of information which can be readily referred to by a health-care provider continues to exist. The CDiC Textbook of Pediatric Diabetes aims to address this very need. The textbook is a result of collaboration between the sponsors of the Changing Diabetes in Children program (CDiC) and the eminent endocrinologists/ diabetologists of the country. The $\mathrm{CDiC}$ program has been launched by Novo Nordisk A/S in collaboration with International Society for Pediatric and Adolescent Diabetes.

The textbook is divided into eight sections with a total of 31 chapters. Each section has been edited by a separate section editors, all of whom have tremendous clinical and research experience in the respective areas. The division of the book into eight sections not only enhances the readability but also enables for quick referencing by a busy practitioner. Despite these sections, the textbook manages to maintain a consistent flow; no difference in the style of writing is apparent when the reader switches from one section to the next. Individual chapters are also written concisely thereby delivering the crux of the information without burdening the reader with complex details. Appropriate illustrations have been used wherever possible to break the monotony of the text.

The emphasis on clinical aspects of pediatric diabetes is apparent throughout; however, the etiological and genetic components have been highlighted adequately. Although the target population for $\mathrm{CDiC}$ is type 1 diabetes, the textbook delivers adequate information on management of pediatric type 2 diabetes as well. Of particular note is the emphasis on psychosocial and psychiatric aspects of pediatric diabetes; the textbook devoted two chapters on these topics. This aspect of pediatric diabetes is of prime importance but often ends up neglected in clinical practice. Psychiatric disorders and psychosocial problems can significantly increase the morbidity and mortality from type 1 diabetes. The information on these topics will be valuable to anyone involved in the care of patients with diabetes. Another point to highlight is the handling of the more complicated topics such as pancreas and islet cell transplantation, continuous glucose monitoring, and insulin pump and genetics of type 1 diabetes mellitus; these chapters have been written in a simplified and lucid manner so as to provide an overview of the topic thereby setting up a base for further reading by an interested reader.

A few chapters of special practical importance include surgery in a child with diabetes and common pitfalls in diagnosis and management. The chapter on insulin therapy explains the insulin technique in the vivid detail - this area is often the Achilles heel of insulin therapy; however, the illustrations provided in the chapter leave little room for error for an attentive reader.

Overall, this textbook is a useful tool for both the busy practitioner as well as the postgraduate student. The information will be instrumental in improving the level of care of patients with pediatric diabetes. However, ensuring the availability of this textbook to all those will be essential in this endeavor.

This concise, well-written book should find a place on the bookshelf of all those involved in the care of pediatric 
diabetes. Even in this era of online information, this textbook will retain its importance for both students as well as experts.

Financial support and sponsorship

Nil.

Conflicts of interest

There are no conflicts of interest.

Nishant Raizada

Department of Endocrinology and Metabolism, All India Institute of Medical Sciences, New Delhi, India

Address for correspondence: Dr. Nishant Raizada, Department of Endocrinology and Metabolism, All India Institute of Medical Sciences, New Delhi, India. E-mail: brideknl@gmail.com
This is an open access journal, and articles are distributed under the terms of the Creative Commons Attribution-NonCommercial-ShareAlike 4.0 License, which allows others to remix, tweak, and build upon the work non-commercially, as long as appropriate credit is given and the new creations are licensed under the identical terms.

For reprints contact: reprints@medknow.com

\begin{tabular}{|l|l|}
\hline \multicolumn{2}{|c|}{ Access this article online } \\
\hline Quick Response Code: & Website: \\
\hline & www.joshd.net \\
\cline { 2 - 2 } & DOI: \\
& 10.4103/joshd.J_Soc_Health_ \\
& Diabetes_28_17 \\
\hline
\end{tabular}

How to cite this article: Raizada N. CDiC textbook of pediatric diabetes: Book review. J Soc Health Diabetes 2018;6:59-60. 